\title{
QUALITY CULTURE IN HIGHER EDUCATION INSTITUTES: PERSPECTIVE OF DIFFERENT STAKEHOLDERS
}

\author{
SAIMA JAWAD ${ }^{1}$, IRAM JAMSHAID ${ }^{2}$, FAZAL WAHAB ${ }^{3}$ \\ ${ }^{1}$ Department of Computer Science, Bahria University, Islamabad, Pakistan \\ saima@bahria.edu.pk \\ ${ }^{2}$ Department of Computer Science, Bahria University, Islamabad, Pakistan \\ iramj@bahria.edu.pk \\ ${ }^{3}$ Department of Computer Science, Bahria University, Islamabad, Pakistan \\ fwahhab@bahria.edu.pk
}

\begin{abstract}
Quality assurance and accreditation have become an essential part of higher education quality management all over the world. To ensure sustainable high quality education, it is essential to develop an internal quality culture in Higher Education Institutes (HEIs). The main objective of this study is to establish existence/non-existence of quality culture by using Internal Quality Culture (IQC) framework. The study will also identify the main impediments in the prevailing organizational culture of a HEI. The framework highlights four dimensions of IQC; Planning, Support, Execution and Assessment. Different indicators for these quality culture dimensions are analyzed by comparing the perspectives of three main stakeholders i.e. faculty, students and management. The results indicate that successful development of quality culture requires commitment and active collaboration of all the stakeholders. Moreover, the changing and conflicting requirements of the stakeholders influence the quality improvements efforts.
\end{abstract}

Keywords: Quality, Quality Culture, Higher Education, Quality Management, Quality Indicators.

1. Introduction. Higher education has become essential for the socio-economic growth of developing countries. Provision of quality higher education has thus become a critical issue in these countries. Pakistan is a developing country with a large higher education sector which caters for 7.4 million students enrolled in 132 HEIs [1]. In Pakistan, the Higher Education Commission (HEC) is committed to quality assurance and the enhancement of higher education sector. The quality improvement in HEIs requires continuity of strategies, actions and efforts as a prerequisite. Quality Assurance and its management is a great challenge to practitioners seeking workable guidelines, evidences of good practices and tools that will facilitate the process [2]. The main challenge for quality education management is to ensure continuous improvement while taking into consideration differing interpretation of educational processes according to the goals and needs of the stakeholders and changing and conflicting requirements of all the stakeholders. The quality management principles have been conceptualized and have been widely implemented all over the world as Total Quality Management (TQM). These quality principles basically represent an organizational culture that uses effective planning, systematic management and active collaboration of all the stakeholders to achieve the mission of the institution [3]. Quality culture is commonly misunderstood as a system of internal quality monitoring. It is important to realize that quality culture is not a process or set of procedures, nor it can be imported and imposed [4]. Quality culture needs development rather than assurance and innovation instead of standards compliance. Development of quality culture requires structural, procedural and behavioral changes at organizational level. Incorporating a cultural change in an organization is a difficult process which involves long term [5]. The quality culture within an organization requires total commitment and devotion to quality of all the stakeholders. Mutual respect, trust and cooperation is the shared responsibility. The IQC framework suggested by [6] embeds quality culture 
in the organizational context as a continuous quality improvement process. The framework protects quality culture from 'over-bureaucratization' by empowering all the stakeholders. The purpose of this study is to analyze and compare different IQC dimensions from the perspective of three main stakeholders i.e. faculty, students and management. The next section provides an overview of the IQC framework, followed by a description of research methodology and discussion of data analysis.

2. The IQC Framework. Fig.1 shows the main structure of the IQC framework consisting of four dimensions: Planning, Support, Execution, and Assessment are shown in Figure 1. More elaboration of these dimensions is given below:

Planning: Strategic policy and planning are the main factors for embedding quality culture in an institution.

Sustainable and long term strategic planning for quality improvement is a challenge for institutional leadership.

Support: A conducive organizational environment and appropriate infrastructure is essential to facilitate and maintain quality culture in HEI. Establishing such an environment involves financial, operational and moral support for all academic and administrative activities.

Execution: Provision of quality teaching and learning experience is the prime responsibility of a HEI. This requires participation, ownership, commitment, effective interaction and teaching learning between all stakeholders. The implementation of the quality policy requires systematic execution of all academic and administrative processes across all departments/units of HEI.

Assessment: Assessment and evaluation of all the major academic and administrative processes against defined quality standards play a very vital role in improving the quality culture. HEIs can use this constructive feedback for the review of quality policy in accordance with the institutional vision/mission.

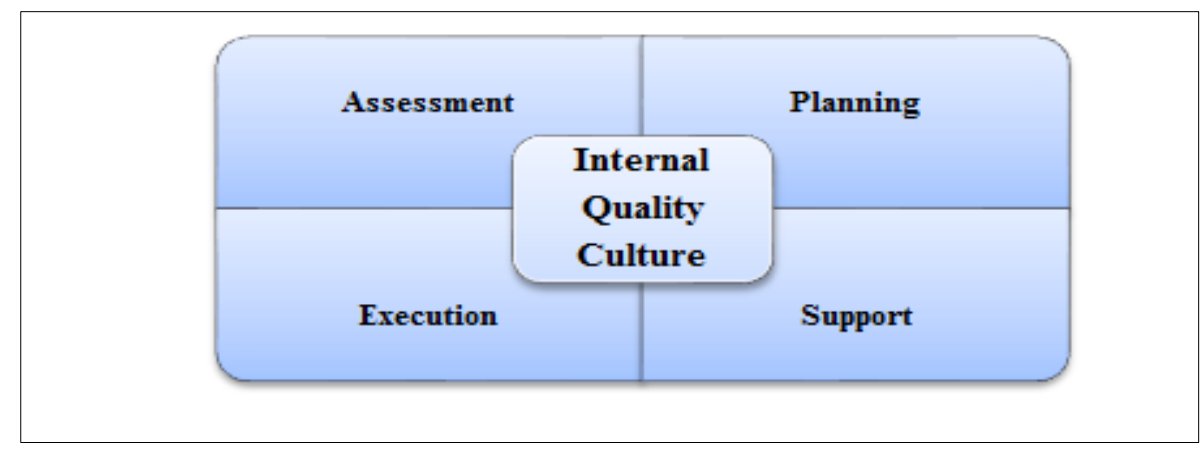

Figure1. The IQC Framework

The IQC framework suggests a four-stage cyclic process for continuous quality improvement to embed quality culture in HEI shown in Figure 2. If properly implemented, it is expected to gradually transform the existing organizational culture into quality culture.

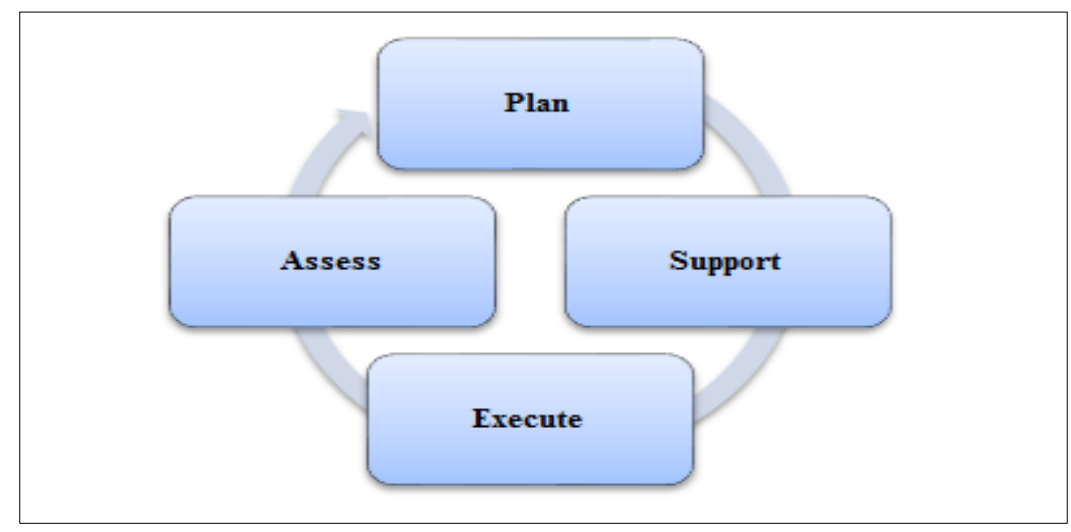

Figure 2. The Continuous Quality Improvement Cycle 
3. Research Methodology. The HEI selected as a case study is BahriaUniversity, Islamabad Campus. The detail of objectives and how the research is conducted is mentioned here.

3.1 Research Objectives. The study is designed to establish the following:

- Existence/nonexistence of the quality culture indicators in the prevailing culture of HEI.

- Identification of main impediments in the development of quality culture in HEI.

- Empowerment of all the stakeholders to protect IQC from over-bureaucratization.

- Justify/validate the IQC framework [6].

Measures of Quality Culture Dimensions: Each of the four above mentioned IQC dimensions are composed of number of indicators given below:

- Planning the indicators are processes/procedures, standards and vision/policies.

- Support the indicators are campus infrastructure, research, financial and administrative support.

- Execution the indicators are participation, commitment, ownership and effective interaction, teaching learning.

- Assessment the indicators are evaluation of academic and administrative processes and constructive feedback.

Questions were framed to measure each of the indicators for the above-mentioned quality culture dimensions. For example, to evaluate the first quality dimension namely planning, we have developed different questions for each of its indicators e.g. vision, mission, processes, standards and procedures. Furthermore, for each of the stakeholder considered in this empirical study, that is faculty, students and management, different questionnaires were prepared in accordance with their specific perspective.

3.2 Data Collection. The primary data for the study was collected through self-administered questionnaires. To measure the IQC dimensions, the required information was extracted by analyzing responses from the respondents. Before conducting the actual study, a pilot study was undertaken so as to measure the reliability of the questionnaires being utilized in the research. Following the pretest exercise, the questionnaires were modified taking into account the difficulties encountered by the respondents. The questions were further simplified so that the terms could be easily comprehended by the respondents, keeping in mind the questionnaire development objectives. Stakeholders were briefed and the objective of the study was explained whenever and wherever required. Finally, the respondents were given sufficient time to complete the questionnaires.

3.3 Population. The population of this study consists of students, faculty members and the management of Bahria University, Islamabad (BUI). The data for this empirical study has been collected during the ongoing semester in the university from students, faculty members and management.

3.4 Development of Instrument. In order to model the development of quality culture in the HEIs, four quality dimensions of IQC framework (Planning, Support, Execution and Assessment)were measured on the basis of multipleitem responses. The research instrument consists of a set of structured questionnaires, in which respondents were asked to indicate their level of preferences. A five-point Likert scale ranging from 0-4 was used with the following description [7]:

0 Uncertain,

1 Very Dissatisfied

2 Dissatisfied

3 Satisfied

4 Very Satisfied

The mean score of the Likert scale is: $(0+1+2+3+4) / 5=2.0$. A mean score of 2.0 and above for a question is considered affirmative and below 2.0 is considered as negative answer[7]. 
3.5 Sampling Plan. In order to collect data from our stakeholders, a sample of 170 respondents was taken. The sample consisted of 114 students, 32 faculty members, and 24 respondents from management. We selected sampling units (respondents) from different departments of BUI campus.

4. Data Analysis and Discussion. The response of the stakeholders is given and discussed one by one in the following sections. The cumulative mean and cumulative standard deviation is mean and standard deviation of each IQC dimension. The analysis determines whether all IQC dimensions' indicators meet the threshold value or not. If the mean value of any indicator is less than the mentioned threshold 2.0, it will be considered as a barrier in the promotion of IQC in HEI. The indicator with smaller mean value reflects its relative weakness.

In the following discussion Cumulative Mean is abbreviated as $\mathbf{C M}$, and Cumulative Standard Deviation is abbreviated as CSD.

Stakeholders' Responses are summarized in tables, and are then presented in the graphs as well. Each stakeholder is analyzed separately and at the end of this section comparison of the three stakeholders is also given.

4.1. Students' Response Analysis. The involvement of students in the development of quality culture is very important. It is therefore important to develop a sense of ownership in them. The result of students' assessments can be an effective source to improve institutional policies and practices. Table 1 to Table 4 show students' response of the indicators for quality culture dimensions: Planning, Support, Execution and Assessment respectively. Elaborating Table 1 for the dimension Planning, its first indicator Procedures/processes has mean value of 2.89 and 0.33 is its standard deviation. 2.97 is the CM for the three indicators of Planning and 0.10 is the CSD for the said indicators. Similar explanation is for all the response tables of the stakeholders. The cumulative mean score value for all the quality dimensions is greater than the threshold value of 2.0. Furthermore, it has been observed that Planning and Assessment are the two quality dimensions which have almost the same cumulative mean scores, 2.97 and 2.96 respectively but Assessment has less standard deviation than planning, while support has the lowest cumulative mean value, namely, 2.75 with the largest cumulative standard deviation 0.11 . Discussing the indicators individually, we observe that Assessment /Evaluation, standards, Teaching/learning and Vision/Policy have almost the same mean scores, while commitment/ownership is considered to be the best since it has the lowest standard deviation i.e.,0.08. Hence we conclude all IQC indicators are at satisfactory level, and Students prove the presence of quality culture.

Table 1. Student Response for Planning

\begin{tabular}{|l|r|r|}
\hline Planning & Mean & StDev \\
\hline Procedures/Processes & 2.89 & 0.33 \\
\hline Standards & 3.01 & 0.19 \\
\hline Vision/Policy & 3.00 & 0.13 \\
\hline Cumulative Mean/SD & 2.97 & 0.10 \\
\hline
\end{tabular}

Table 3. Student Response for Execution

\begin{tabular}{|l|r|r|}
\hline Execution & Mean & StDev \\
\hline Participation & 2.82 & 0.19 \\
\hline Commitment/Ownership & 2.89 & 0.08 \\
\hline Effective interaction & 2.86 & 0.21 \\
\hline Teaching/learning & 3.01 & 0.22 \\
\hline
\end{tabular}

Table2. Student Response for Support

\begin{tabular}{|l|r|r|}
\hline Support & Mean & StDev \\
\hline Campus Infra Structure & 2.80 & 0.29 \\
\hline Financial Support & 2.68 & 0.40 \\
\hline Admin Support & 2.85 & 0.37 \\
\hline Research Support & 2.67 & 0.16 \\
\hline Cumulative Mean/SD & 2.75 & 0.11 \\
\hline
\end{tabular}

Table 4. Student Response for Assessment

\begin{tabular}{|l|r|r|}
\hline Assessment & Mean & StDev \\
\hline Feedback & 2.90 & 0.15 \\
\hline Assessment/Evaluation & 3.01 & 0.14 \\
\hline Cumulative Mean/SD & 2.96 & 0.01 \\
\hline
\end{tabular}




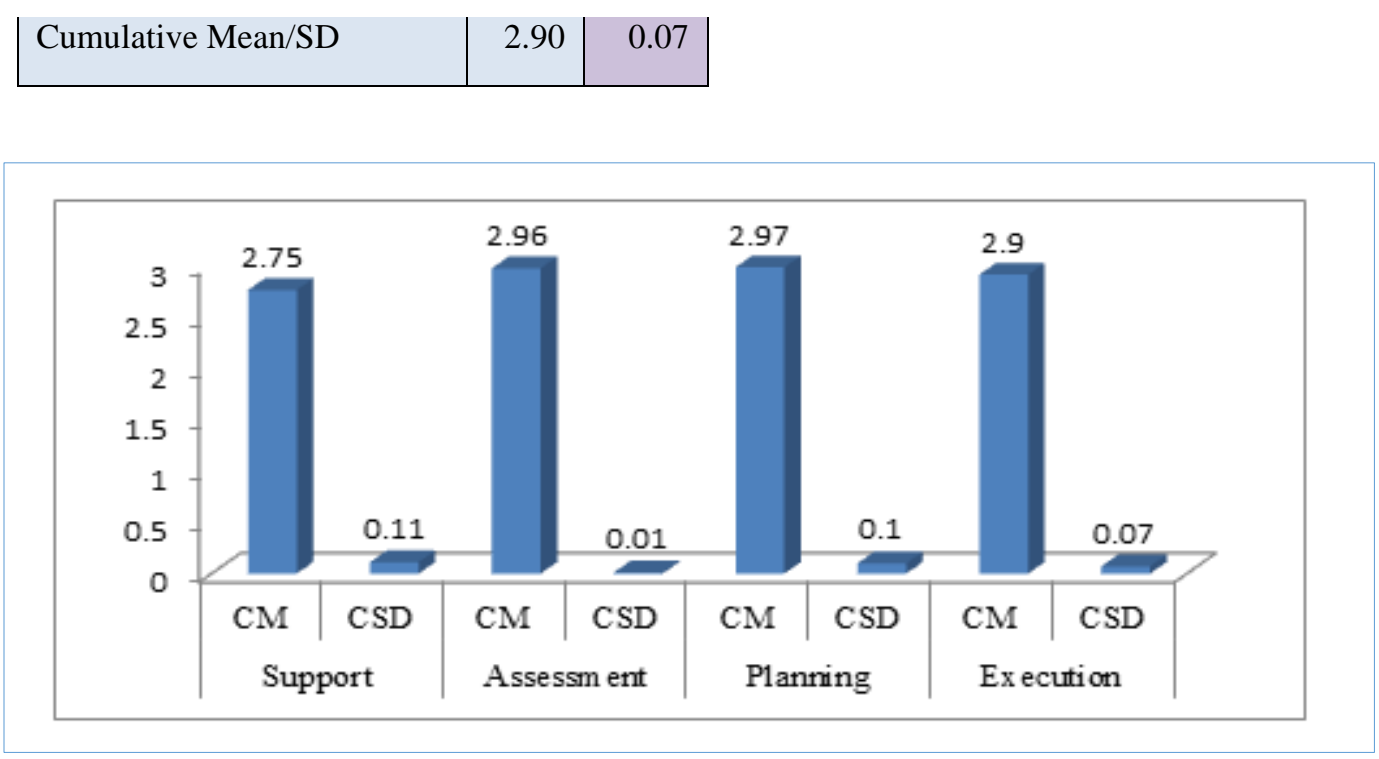

Figure 3. Students' Response Analysis

In figure 3 we can see that all the IQC indicators are fairly above 2 which means that students are affirming the existence of quality culture in Bahria University.

4.2. Faculty's Response Analysis. Qualified and committed faculty is an asset of a HEI. Table 5 to Table 8 show faculty response. It is observed that all the four quality dimensions have cumulative mean score value greater than 2.0 . However, all the cumulative mean values are less than the cumulative mean values of students. Among the four quality dimensions for the faculty, 'planning' has the highest cumulative mean score 2.57, and largest standard deviation 0.46 , indicating that faculty does not share a consistent opinion for 'planning' of the university. This can be very obviously seen in Figure 4. Individually discussing the indicators for the faculty, we see that 'standards' has the highest mean score (with surprisingly largest standard deviation i.e.,1.05), followed by commitment/ownership, participation and campus environment and others, while research support has the lowest mean score. We conclude that faculty affirms the existence of IQC in the institute.

Table 5. Faculty Response for Planning

\begin{tabular}{|l|r|r|}
\hline Planning & Mean & StDev \\
\hline Procedures/Processes & 2.39 & 0.44 \\
\hline Standards & 3.05 & 1.05 \\
\hline Vision/policy & 2.28 & 0.16 \\
\hline Cumulative Mean/SD & 2.57 & 0.46 \\
\hline
\end{tabular}

Table 7. Faculty Response for Execution

\begin{tabular}{|l|r|r|}
\hline Execution & Mean & StDev \\
\hline Participation & 2.50 & 0.10 \\
\hline
\end{tabular}

Table 6. Faculty Response for Support

\begin{tabular}{|l|r|r|}
\hline Support & Mean & StDev \\
\hline Campus Infra Structure & 2.49 & 0.41 \\
\hline Financial Support & 2.29 & 0.30 \\
\hline Admin Support & 2.15 & 0.46 \\
\hline Research Support & 2.06 & 0.39 \\
\hline Cumulative Mean/SD & 2.25 & 0.07 \\
\hline
\end{tabular}

Table 8. Faculty Response for Assessment

\begin{tabular}{|l|r|r|}
\hline Assessment & Mean & StDev \\
\hline Feedback & 2.37 & 0.23 \\
\hline
\end{tabular}




\begin{tabular}{|c|c|c|c|c|c|}
\hline Commitment/ownership & 2.52 & 0.18 & Assessment/ Evaluation & 2.37 & 0.25 \\
\hline Effective interaction & 2.25 & 0.31 & Cumulative Mean/SD & 2.37 & 0.01 \\
\hline Teaching/learning & 2.31 & 0.08 & & & \\
\hline Cumulative Mean/SD & 2.40 & 0.10 & & & \\
\hline
\end{tabular}

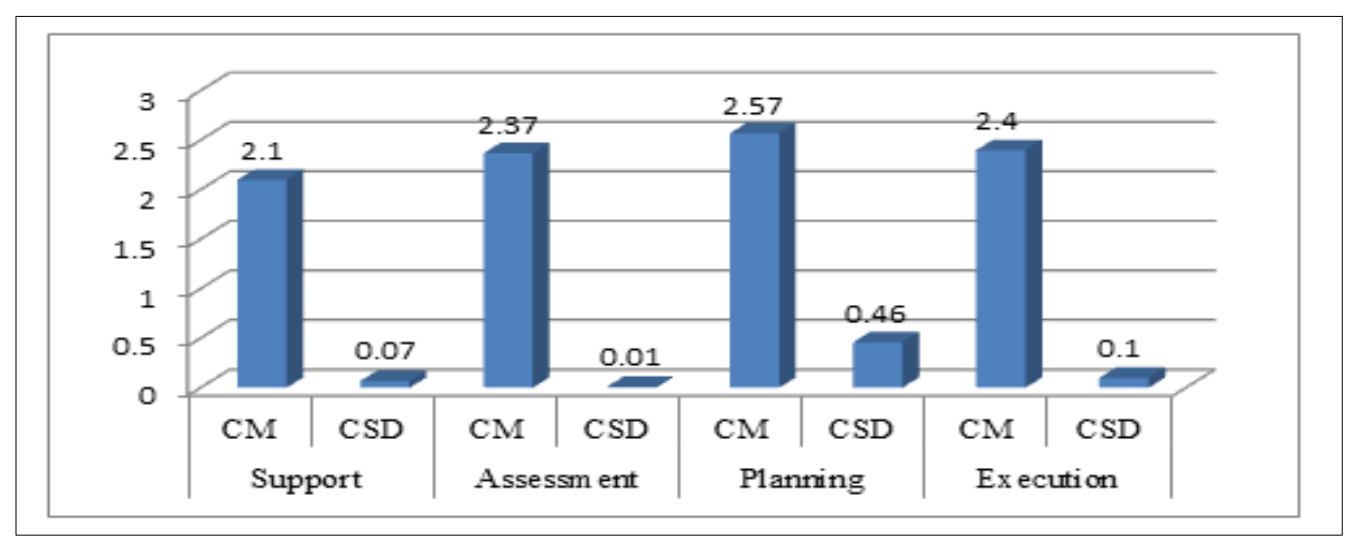

Figure 4. Faculty's Response Analysis

4.3. Management's Response Analysis. The institutional management also plays a major role in quality culture. Without management and administrative support, quality culture can neither be implemented nor be sustained. The results are recorded in Table 9, Table 10, Table 11, and Table 12.We observe that quality dimensions have cumulative mean score value greater than 2.0. We note that all the values of the quality dimensions are less than the values of the stakeholder students but greater than the faculty. Planning has the highest cumulative mean score 2.77 with standard deviation, 0.07, while the Assessment has the lowest cumulative mean score with 0.08 standard deviation. Individually speaking the indicator, 'standards' has the highest mean score, followed by commitment/ownership, procedures/processes, and campus environment/infrastructure, while research support has the minimum mean score. While comparing the results in Figure 5 we observe that all the support indicators have the highest standard deviation, and at the same time we view that all the IQC indicators for the institute management are above satisfactory level.

Table 9. Management Response for Planning

\begin{tabular}{|l|r|r|}
\hline Planning & \multicolumn{1}{l|}{ Mean } & \multicolumn{1}{l|}{ StDev } \\
\hline Procedures/Processes & 2.82 & 0.30 \\
\hline Standards & 2.94 & 0.33 \\
\hline Vision/policy & 2.56 & 0.43 \\
\hline Cumulative Mean/SD & 2.77 & 0.07 \\
\hline
\end{tabular}

Table 11. Management Response for Execution

\section{Execution}

Mean $\quad$ StDev

Table10. Management Response for Support

\begin{tabular}{|l|r|r|}
\hline Support & Mean & StDev \\
\hline Campus Infra Structure & 2.6 & 0.77 \\
\hline Financial Support & 2.6 & 0.66 \\
\hline Admin Support & 2.70 & 0.69 \\
\hline Research Support & 2.55 & 0.47 \\
\hline Cumulative Mean/SD & 2.61 & 0.13 \\
\hline
\end{tabular}

Table 12. Management Response for Assessment

\begin{tabular}{|l|l|l|}
\hline Assessment & Mean & StDev \\
\hline
\end{tabular}




\begin{tabular}{|l|r|r|}
$\begin{array}{l}\text { Participation/Effective } \\
\text { interaction }\end{array}$ & 2.56 & 0.37 \\
\hline Commitment/Ownership & 2.88 & 0.29 \\
\hline Effective interaction & 2.49 & 0.27 \\
\hline Teaching/learning & 2.89 & 0.36 \\
\hline Cumulative Mean/SD & 2.70 & 0.05 \\
\hline
\end{tabular}

\begin{tabular}{|l|r|r|} 
Feedback & 2.62 & 0.37 \\
\hline Assessment/Evaluation & 2.59 & 0.25 \\
\hline Cumulative Mean/SD & 2.60 & 0.09 \\
\hline
\end{tabular}

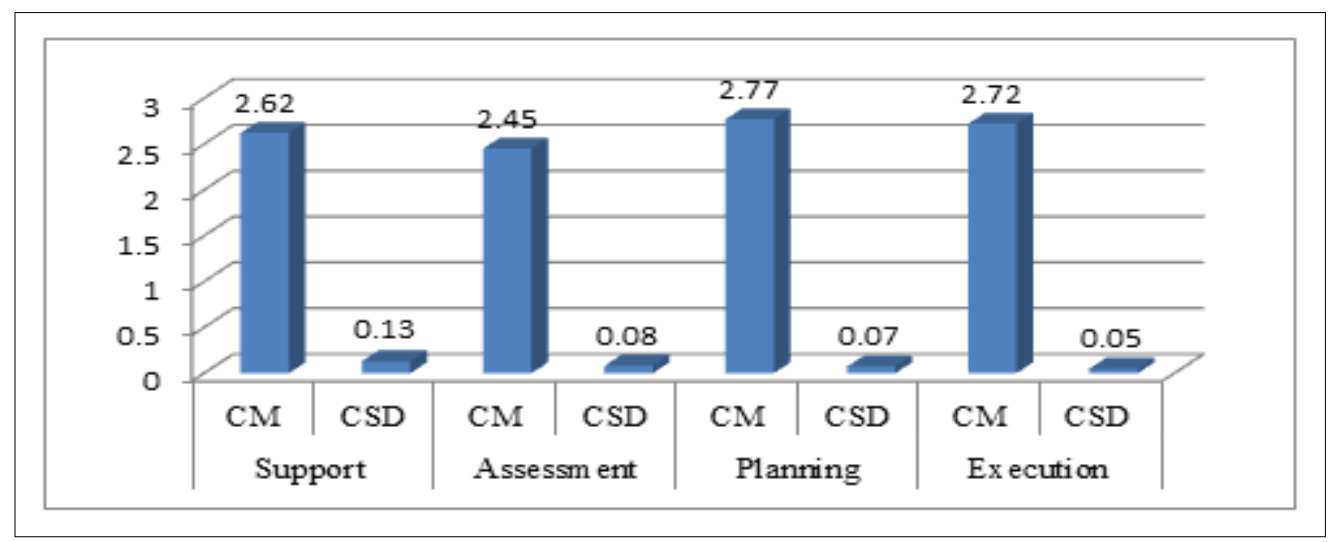

Figure 5. Management's Response Analysis

4.2. Comparative Analysis of Stakeholders. The CMs and CSDs are put into one table for comparison. The results affirm the presence of IQC dimensions but of course there is variation in the stake holders' view points which can be interpreted in a better way in figure 6 .

Table 13. The Stakeholders' CMs and CSDs for IQC Dimensions

\begin{tabular}{|l|r|r|r|r|r|r|r|r|}
\hline & \multicolumn{2}{|c|}{ Support } & \multicolumn{2}{c|}{ Assessment } & \multicolumn{2}{c|}{ Planning } & \multicolumn{2}{c|}{ Execution } \\
\hline & \multicolumn{1}{|c|}{ CM } & \multicolumn{1}{l|}{ CSD } & CM & CSD & CM & CSD & CM & CSD \\
\hline Student & 2.75 & 0.11 & 2.96 & 0.01 & 2.97 & 0.1 & 2.9 & 0.07 \\
\hline Faculty & 2.1 & 0.07 & 2.37 & 0.01 & 2.57 & 0.46 & 2.4 & 0.1 \\
\hline Management & 2.62 & 0.13 & 2.45 & 0.08 & 2.77 & 0.07 & 2.72 & 0.05 \\
\hline
\end{tabular}




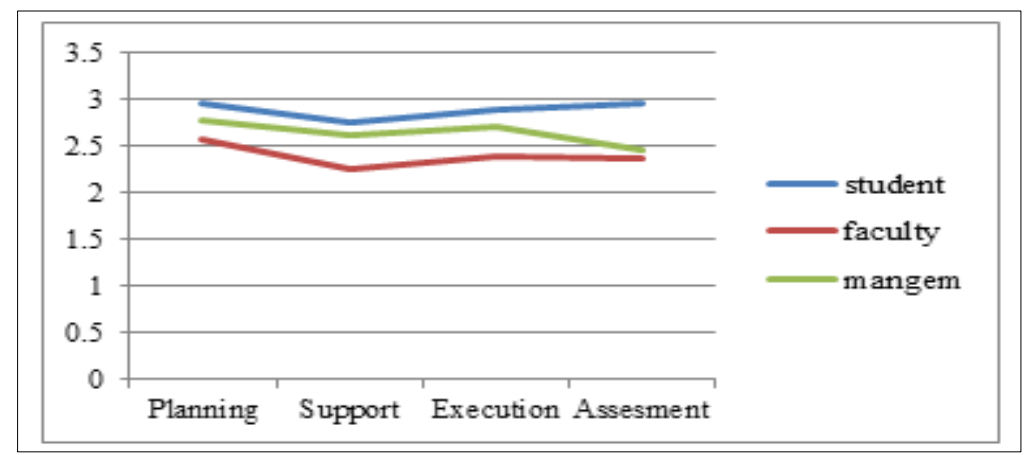

Figure 6. Comparative Analysis of Stakeholders

The three stakeholders, no doubt, confirm the existence of IQC, but we do not find any intersection in the curves of the three internal stakeholders. Students curve at the top and faculty's curve at the bottom with management in the center reflects that faculty would like to bring more improvement in all the quality culture dimensions.

5. Conclusion. Development of quality culture requires committed efforts for continuous quality improvements while considering the changing and conflicting requirements of all the stakeholders. The IQC framework has been validated through the Bahria University Case study and the findings are: the value of each indictor is composed of the responses of every stakeholder which means that every stakeholder is equally important in the development of IQC and hence it can be concluded that this framework can protect IQC from over-bureaucratization and ensures empowering of all the stakeholders. Moreover, the results of this study shows that this framework can be used as a tool for determining existence/nonexistence of the quality culture indicators in the prevailing culture of HEI and for identification of main impediments in the development of quality culture in HEI.

In future IQC of inter HEIs, and intra HEIs can be evaluated. On the basis of which we can do comparative analysis of the existing quality culture of HEIs at local and national level. Further this framework can also be used as a measuring stick for the improvement of IQC in HEIs as well.

\section{REFERENCES}

[1] Batool, Z., and R. H. Qureshi. "Quality Assurance Framework for Higher Education: Pakistani Context." Published by www. hec. gov.pk (2007).

[2] Batool, Z. and Qureshi, R. (2009). Quality Assurance Manual for Higher Education in Pakistan, Higher Education Commission, Islamabad, Pakistan.

[3] Freed, J. E., Klugman M. R. and Fife, J. D. (1997). "A Culture for Academic Excellence: Implementing the Quality Principles in Higher Education”, ASHE-ERIC Higher Education Report series Vol. 25 No. 1.

[4] Harvey, L. (2009). "A Critical Analysis of Quality Culture", Online: Downloaded from http://www.inqaahe.org/admin/files/...documenten/1241773373_16-harvey-a-critical-analysis-of-qualityculture.pdfJuran, J. M. (1987). Management of Quality, Juran Institute. Inc, Wilton.

[5] Ehlers, U.D. (2009) “Understanding Quality Culture”, Quality Assurance in Education, Vol 17 No. 4, pp. 343-363

[6] Wahab, F., Jawad, S. \&Jamshaid, I., (2010). A Framework for Embedding Internal Quality Culture in Higher Educational Institutes of Pakistan, Proceedings of 3rd International Conference on Assessing Quality in Higher Education ICAQHE, December, 2010, Lahore, Pakistan, Pages.296-309.

[7] Harry N. Boone, Jr., Deborah A. Boone (2012). "Analyzing Likert Data”, Journal of Extension, Volume 50 No 2 